\title{
The Use of Carbamazepine (Tegretol) in Psychiatry and Its Association to Kindling, Temporal Lobe Epilepsy and Psychopathology
}

James Stanch, M.D.

Thomas Jefferson University Hospital

Follow this and additional works at: https://jdc.jefferson.edu/jeffjpsychiatry

Part of the Psychiatry Commons

Let us know how access to this document benefits you

\section{Recommended Citation}

Stanch, M.D., James (1984) "The Use of Carbamazepine (Tegretol) in Psychiatry and Its Association to Kindling, Temporal Lobe Epilepsy and Psychopathology," Jefferson Journal of Psychiatry. Vol. 2 : Iss. 1 , Article 7.

DOI: https://doi.org/10.29046/JJP.002.1.003

Available at: https://jdc.jefferson.edu/jeffjpsychiatry/vol2/iss1/7

This Article is brought to you for free and open access by the Jefferson Digital Commons. The Jefferson Digital Commons is a service of Thomas Jefferson University's Center for Teaching and Learning (CTL). The Commons is a showcase for Jefferson books and journals, peer-reviewed scholarly publications, unique historical collections from the University archives, and teaching tools. The Jefferson Digital Commons allows researchers and interested readers anywhere in the world to learn about and keep up to date with Jefferson scholarship. This article has been accepted for inclusion in Jefferson Journal of Psychiatry by an authorized administrator of the Jefferson Digital Commons. For more information, please contact: JeffersonDigitalCommons@jefferson.edu. 


\title{
THE USE OF CARBAMAZEPINE (TEGRETOL) IN PSYCHIATRY AND ITS ASSOCIATION TO KINDLING, TEMPORAL LOBE EPILEPSY AND PSYCHOPATHOLOGY
}

\author{
JAMES STANCH, M.D.
}

The recent theory of kindling may help to link neurophysiologic, neurotransmitter and neuroanatomic mechanisms important in understanding the neurology of behavior. Limbic kindling is of interest in developing models of epilepsy, psychosis, learning and memory (1-5). Kindling might explain the late development of psychopathology.

This paper will first define kindling and demonstrate how kindling offers a model within which to view more prolonged behavioral deviations as neurophysiological processes. The use of carbamazepine and its association to kindling, temporal lobe dysfunction and psychopathology will be discussed.

As originally defined by Goddard and Morrel (2), the term kindling referred to the observation that brief electrical stimulation of limbic and cortical areas in rats by currents that were originally inadequate to evoke after-discharges or behavioral effects, eventually produces an after-discharge. When carried on long enough, kindling stimulation leads to spontaneous seizures. As suggested by the name, the term kindling is an analogy to the starting of a fire whereby application of low heat (or subthreshold stimulation) causes wood (or brain tissue) to burst into flames (or convulse). Kindling represents neuronal processes that may mediate the formation of lasting behavioral change. The process of kindling is not all or none (3). It involves a progressive, lasting lowering of neuronal threshold to evoke an afterdischarge. Both electrical and chemical stimuli can produce kindling (7). Chronic administration of CNS stimulants such as cocaine and amphetamines may cause increases in limbic system discharges and vulnerability to pathologic behavior and seizures $(8,9)$.

The concept of kindling has been applied to chronic psychological stress that results in progressive vulnerability to pathologic behavior. It is known that environmental events can induce synchronized electrical activity within the limbic system. There is evidence of lasting change in behavior following repeated limbic stimulation with and without changes in epileptogenicity. Animal studies have shown full-blown behavioral convulsions after epileptic activation of the limbic system without electroencephalographic evidence of seizures. It is not completely clear what role interictal phenomena have on behavioral responses (10). Kindling may explain why certain temporal lobe epilepsy (TLE) patients develop behavioral changes and psychosis.

Dr. Stanch is a second-year resident in Psychiatry. 


\section{Temporal Lobe Epilepsy (TLE)}

I would like to focus on temporal lobe epilepsy (TLE), a condition associated with personality disturbances $(11,12)$. Eighty-five percent of all persons with epilepsy have temporal lobe-limbic system epilepsy, in which the temporal lobe recruits the rest of the brain into a major motor seizure (13). Some of the psychic experiences which may occur during temporal lobe dysfunction that can mimic psychiatric disorders are the following $(13,14)$ :

Hallucinations (auditory, visual, olfactory, tactile, gustatory or vertiginous)

Depersonalization

Deja vu

Jamais vu

Derealization

Fear

Paranoia

Elation

Depression

Anxiety

Sexual disturbances

Cephalgic auras (micropsia, macropsia)

Crying and laughing episodes
Excessive water drinking

Dreamy state

Forced thinking

Compulsive thinking

Confusion

Amusia

Aphasia

Agnosia

Memory defects

Hypergraphia

Hyperreligiosity

Headache

Alimentary symptoms

Running episodes

Thus it is not enough to ask a patient suspected of having TLE whether he has seizures, convulsions or attacks of unconsciousness, and to leave it at that. History-taking in these cases demands a meticulous search for the more subtle types of temporal lobe attacks.

There are technical problems in identifying patients with temporal lobe-limbic system dysfunction manifesting clinically as psychiatric disorders, i.e., explosive, aggressive, borderline and antisocial personality structures $(13,14,15)$. These individuals exhibit a wide variety of episodic behavioral disturbances including free-floating anxiety, affective disorders, impulsive destructive rages, atypical psychosis and mini-psychotic episodes $(14,15,16,17)$. Some of these patients demonstrate abnormal EEG activity, with clinical improvement after anticonvulsant medication (18). The problem is that temporal lobe-limbic system abnormalities, whether associated with an ictal or interictal state, are seldom detected by cortical, much less scalp, recordings; thus the clinical EEG is not a sensitive measure of possible neurophysiological correlates with behavior (19). In the future, computerized analysis of EEG and evoked potential data and Positron Emission Tomography (PET) could be helpful $(20,21)$. In the meantime, physiological and drug-activated EEG's (sleep, hyperventilation, sedatives and stimulants) with low temporal lobe leads or nasopharyngeal leads are presumed to be the most useful clinical measures of central nervous system instability $(22,23)$. 
The concept of psychosis and epilepsy has been written about for the last 200 years. In 1860 Morel reported the alternation of psychotic episodes with convulsions. Lateralization was introduced into the work by Flor-Henry who reported left-sided TLE being more frequently associated with schizophrenic-like symptoms and rightsided lesions being associated with affective disorders (10).

Monroe has data that directly support the concept of limbic ictus as an etiological mechanism in a group of patients with the diagnosis of atypical psychosis. Psychoses were correlated with electrographic data recorded from chronically implanted subcortical electrodes $(14,16,17,22,23,24,25,26)$. Monroe describes a young female patient diagnosed as having chronic paranoid schizophrenia who would become psychotic with intense rage reactions. At this time dramatic electrographic abnormalities from subcortical electrodes were noted although these abnormalities were not present in the corresponding scalp leads. During the intervals between attacks when her chronic paranoid symptoms were the only deviant behavior noted, interictal types of recordings were noted from subcortical electrodes (17). Ictal fear has been found by neurosurgeons, who have implanted electrodes in the brain, to arise from a medial temporal focus in the region of the amygdala and hippocampus, i.e., limbic system lesions as opposed to lateral cortical lesions $(3,12)$. A recent study by Hermann showed that a subgroup of TLE patients did have abnormal MMPI test data. This subgroup was composed of TLE patients whose seizures began with fear (25). These patients showed elevated scores of MMPI Psychasthenia and Paranoia scales.

The following question arises; is the psychosis seen in epilepsy related to the psychosis seen in non-epileptic patients? Perez and Trimble performed a recent study on 24 patients with psychosis and epilepsy and 11 controls that just had psychosis diagnosed clinically by two different psychiatrists $(27,28)$. The technique used the examination of Wing (27). This examination collects symptoms by a standard interview. This information is put into a computer using a special program which then yeilds a computerized diagnosis of the psychosis to objectify the diagnosis. Twelve of the epileptic psychotics were diagnosed as having a form of schizophrenia. The other half had various other diagnoses. Eleven of the twelve had the nuclear schizophrenia which was based on Schneiderian first rank symptoms. The group was divided up into those that had generalized epilepsy and those that had TLE. This diagnosis was done clinically and by an EEG. The results showed that only those patients with the nuclear schizophrenia described by Schneider had TLE. Nuclear schizophrenia did not occur in generalized epilepsy.

This is the most objective evidence obtained so far linking nuclear schizophrenia and TLE. The study also looked at the profile between left and right TLE. The nuclear syndrome appeared significantly more in left TLE. The laterality was established by an independent electroencephalographer, the diagnosis of nuclear schizophrenia by a computer. This is a direct confirmation of the observations made in the sixties by Flor-Henry of a direct link between left-sided TLE and nuclear schizophrenia (10, 26).

Studies supporting Flor-Henry's observation of right sided temporal lobe epilepsy 
in the nondominant hemisphere yielding affective psychosis can be found in the literature $(10,26)$. It is also important to note that in the majority of TLE patients the epilepsy precedes the psychosis by several years.

\section{Carbamazepine}

Carbamazepine (CBZ) (Tegretol) was developed by J.R. Geigy in Basel, Switzerland, in the 1950's (29). Its anticonvulsant properties were described by Theobold and Krinz in 1963, based on animal studies. The compound was introduced in Europe as an antiepileptic in the early 1960's. Not until 1974 was CBZ approved for use in epilepsy in the U.S. CBZ is chemically related to the tricyclic antidepressants, such as imipramine.

The drug of choice for temporal lobe epilepsy is CBZ (13). Most patients with uncontrolled temporal lobe epilepsy have severe personality problems. There is a dramatic change in behavior with control of the epilepsy, not seen with the use of phenytoin and phenobarbital. Evidence has been accumulated which inicates that CBZ has beneficial psychotropic effects. Initially these effects were noted in psychiatric syndromes associated with seizure disorders $(30,31)$.

CBZ has shown clinical usefulness in the following disorders:

1. Temporal lobe epilepsy (TLE, Partial complex seizures) $(1,32)$

2. Grand mal seizures (32)

3. Alcohol withdrawal seizures (33)

4. Mixed seizure patterns (32)

5. Kindling phenomenon in amygdala $(34,35,36,37)$

6. Trigeminal neuralgia $(38,39,40)$

7. Tabes dorsalis $(40,41)$

8. Paraesthesias associated with multiple sclerosis

9. Paraesthesias associated with phantom limb (42)

10. Postherpetic neuralgia (43)

11. Glossopharygeal neuralgia (44)

12. Digitalis-induced ventricular arrhythmias (45)

13. Motor and verbal tics in Gilles de la Tourette's syndrome $(46,47)$

14. Myokymia $(48,49)$

15. Myoclonic tinnitus $(50,51,52,53)$

16. Manic depressive illness $(1,3,14,54-66)$

17. Affective dysregulation of TLE (31)

18. Borderline personality disorder $(1,14,15)$

19. Atypical psychosis (14)

20. Episodic dyscontrol syndrome $(3,14,17)$

21. Limbic ictus with atypical psychosis $(12,14,66)$

22. Schizophrenia $(12,60,64)$

23. Diabetes insipidus $(67,68,69)$

A mechanism which would explain the spectrum of usefulness of CBZ from 
paroxysmal or shooting pain to affective dysregulation is still unclear. Theories as to the antidepressant and antimanic effects of $\mathrm{CBZ}$ have been related to the noradrenergic system and its ability to stabilize limbic system dysfunction. The possibility of a previously undescribed antipsychotic effect or anticonvulsant (antikindling) effect has to be considered. CBZ effects on GABA, opiates, vasopressin, somatostatin are but a few areas of interest $(1,3,62,67,68,69,70)$.

Although a number of theories suggest various mechanism of action of CBZ, none fully elucidates the molecular mechanism of action and the observed clinical efficacy of this extremely important and interesting drug.

\section{REFERENCES}

1. Post, R, Uhde T, Putnam, F, Ballenge, J, and Berrettini W: Kindling and carbarbamazepine in affective illness. The Journal of Nervous and Mental Disease 170: 717-731, 1982

2. Goddard, GV, and Morrell F: Chronic progressive epileptogenesis induced by focal electrical stimulation of brain. Neurology (NY) 21: 393, 1971

3. Ademec, R, and Stark Adamec, C: Limbic kindling and animal behavior-implications for human psychopathology associated with complex partial seizures. Biological Psychiatry 18: 269-292, 1983

4. Goddard, GV, McIntyre, DC, and Leech, CK: A permanent change in brain function resulting from daily electrical stimulation. Exp Neurol 25: 295-330, 1969

5. Goddard, GV, and Douglas, RM: Does the engram of kindling model the engram of normal long-term memory? Can J Neurol Sci 2: 385-394, 1975

6. Heath, RG: Brain function and behavior in emotion and sensory phenomena in psychotic patients and in experimental animals. $J$ Nerv Ment Dis 160: 159-175, 1975

7. Racine, R: Kindling: The first decade. Neurosurgery 3: 234-252, 1978

8. Post, RM, and Ballenger, JC: Kindling models for the progressive development of behavioral psychopathology; Sensitization to electrical, pharmacological, and psychological stimuli, in van Praag HM, Lader MH, Rafaelson OJ, et al., Eds. Handbook of Biological Psychiatry, Part IV, Marcel Dekker, New York, 1981 pp. 609-651

9. Post, RM, and Kopanda, RT: Cocaine, kindling, and psychosis. Am J Psychiatry 133: $627-634,1976$

10. Flor-Henry, P: On certain aspects of the localization of the cerebral systems regulating and determining emotion. Biological Psychiatry 14, 1979

11. Geschwind N: Introduction to psychiatric complications in the epilepsies: Current research. McLean Hosp. J. June (Special Issue): 6-8 (1977)

12. Monroe, RR: Limbic ictus and atypical psychosis. J Nerv Ment Dis 170: 711-716, 1982

13. Schwartzman, Robert, Neurologic disorders presenting as psychiatric illness. Audio-Digest Psychiatry, Vol. 12, No. 13, 1983

14. Neppe, VM: Non epileptic symptoms of temporal lobe dysfunction. South African Journal of Medicine 25: 989-991, 1981

15. Andrulonis, PA, Glueck, BC, Stroebel, CF, and Vogel, NG: Borderline personality subcategories. J Nerv Ment Dis 170: 670-679, 1982

16. Monroe, R: Brain Dysfunction in Aggressive Criminals, D. C. Health, Lexington, Mass., 1978

17. Monroe, R: Episodic Behavioral Disorders. Harvard University Press, Cambridge, Mass., 1970 
18. Andrulonis, PA, Donnelly, J, Glueck, BC, et al. Preliminary data on ethosurximide and the episodic dyscontrol syndrome. Am J Psychiatry 137: 1455-1456, 1980

19. Heath, R: Ed. Studies in Schizophrenia. Harvard University Press, Cambridge, Mass., 1954

20. John, E, Darmel, B, Corning, W, et al. Neurometric Science 196: 1393-1410, 1977

21. Sokoloff L: The deoxyglucose method: Theory and practice. Eur Neurol 20: 137-145, 1981

22. Heath, R: Correlation of brain function with emotional behavior. Biol. Psychiatry 11: $463-480,1976$

23. Mark, V, and Ervin, F: Violence and the Brain. Harper \& Row, New York, 1970

24. Sem-Jacobsen, C, and Torkildsen, A: Depth recording and electrical stimulation in human brain. In Ramey ER, and O'Doherty DS, Eds., Electrical Studies on the Unanesthetized Brain. Hoeber Medical Division, Harper \& Row, New York, 1960

25. Hermann, DP: Interictal psychopathology in patients with ictal fear: A quantitative investigation. Neurology 32: 7-11, 1982

26. Flor Henry, P: Determinants of Psychosis in epilepsy laterality and forced normalization. Biological Psychiatry 18: 331-339, 1983

27. Trimble, R: Epilepsy, Psychiatric aspects of neurological disease, Audio-Digest Foundation Psychiatry 11: No. 19, 1982 (tape)

28. Perez, MM, Trimble, MR: Epileptic psychosis diagnostic comparison with process schizophrenia. Br J Psychiatry 137: 245-249, 1980

29. Theobald, W, and Kunz, HA: Zur Pharmacologie des Antiepilepticums 5-carbamyl-5H dibenze (b,f)azepin. Arzneim Forsch 13: 122-125, 1963

30. Dalby, MA: Anti-epileptic and psychotropic aspects of CBZ in the treatment of Psychomotor epilepsy. Epilepsia 12: 325-334, 1971

31. Dalby, MA: Behavioral effects of carbamazepine. In Penry JK, and Daly DD: Eds., Complex Partial Seizures and Their Treatment. Advances in Neurology 11. Raven Press, New York, 1975 , pp. 331-343

32. Penry, JK, and Daly, DD: Complex partial seizures and their treatment: Advances in Neurology 11, Raven Press, New York, 1975

33. Chu, NS: Carbamazepine: Prevention of alcohol withdrawal seizures. Neurology (NY), 29: 1397-1401, 1979

34. Albright, PS, and Burnham, WM: Development of a new pharmacological seizure model: Effects of anticonvulsants on cortical- and amygdala-kindled seizures in the rat. Epilepsia 21: $681-689,1980$

35. Babington, RG: The pharmacology of kindling. In Hanin I, and Usdin E: Eds., Animal Models of Psychiatry and Neurology, pp. 141-149. Pergamon Press, New York, 1977

36. Ashton, D, and Wauquier, A: Behavioral analysis of the effects of 15 anticonvulsants in the amygdaloid kindled rat. Psycho-pharmacology (Berlin), 65: 7-13, 1979

37. Wada, JA, Sato, M, Wake, A, et al: Prophylactic effects of phenytoin, phenobarbital, and carbamazepine examined in kindled cat preparations. Arch Neurol 33: 426-434, 1976

38. Bonduelle, M: Current approaches to the treatment of trigeminal neuralgia, in Birkmayer, W: Ed., Epileptic Seizures-Behavior-Pain. Huber, Bern, 1975 pp. 321-326

39. Blom, S: Trigeminal neuralgia: Its treatment with a new anticonvulsant drug G32883. Lancet 1: 839-840, 1962

40. Killian, JM, and Fromm, GH: Carbamazepine (Tegretol) in the treatment of neuralgia: Use and side effects. Arch Neurol 19: 129-136, 1968

41. Henry, EV: Oculogyric crises and carbamazepine. Arch Neurol 37: 326, 1980 
42. Davies, EH: Clinical trials of Tegretol in trigeminal neuralgia. Headache 9: 77-82, 1969

43. Yang, CP, and Nagaswami, S: Cardiac syncope secondary to glossopharyngeal neuralgiaEffectively treated with carbamazepine, J Clin Psychiatry 39: 776-778, 1978

44. Corday, E, Enescu, V, Vyden, JK, et al: Antiarrhythmic properties of carbamazepine. Geriatrics 26: 78-82, 1971

45. Steiner, C, Wit, AL, Weiss, MB, et al: The antiarrhythmic actions of carbamazepine (Tegretol). J Pharmacol Exp Ther 173: 323-335, 1970

46. Zawadzki, Z: Treatment of maladie de tics with carbamazepine. Pediatr Pol 47: 11051110,1972

47. Lutz EG: Alternative drug treatments in Gilles de la Tourette's syndrome-Letter to the editor. Am J Psychiatry 134: 95-96, 1977

48. Hughes, RC, and Matthews, WB: Pseudo-myotonia and myokymia $J$ Neurol Neurosurg Psychiatry 32: 11-14, 1969

49. Katrak, SM, Pollock, M, O'Brien, CP, et al: Clinical and morphological features of gold neuropathy. Brain 103: 671-693, 1980

50. Hess, JC, Viada, J, and May, A: Evaluacion de la prueba de la lidocaina y del tratamiento con carbamazepine en pacientes con tinnitus. Rev Otorrinolaringol 40: 5-10, 1980

51. Melding, PS, and Goodey, RJ: The treatment of tinnitus with oral anticonvulsants. $J$ Laryngol Otol 93: 111-122, 1979

52. Rahko, T, and Hakkinen, V: Carbamazepine in the treatment of objective myoclonus tinnitus. J Laryngol Totl 93: 123-127, 1979

53. Shea, JJ, and Harell, M: Management of tinnitus aurium with lidocaine and carbamazepine. Laryngoscope 88: 1477-1484, 1978

54. Ballenger, JC, and Post, RM: Carbamazepine (Tegretol) in manic-depressive illness: A new treatment. Am J Psychiatry 137: 782-790, 1980

55. Ballenger, JC, and Post, RM: Therapeutic effects of carbamazapine in affective illness: A preliminary report. Commun Psychopharmacol 2: 159-175, 1978

56. Okuma, T, Inanaga, K, Otsuki, S, et al: Comparison of the antimanic efficacy of carbamazepine and chlorpromazine: A double-blind controlled study. Psychopharmacology (Berlin) 66: 211-217, 1979

57. Okuma, T, Inanaga, K, Otsuki, S, et al: A preliminary double-bind study of the efficacy of carbamazepine in prophylaxis of manic-depressive illness. Psychopharmacology (Berlin) 73: 95-96, 1981

58. Okuma, T, Kishimoto, A, Inoue, K, et al: Anti-manic and prophylactic effects of carbamazepine on manic-depressive psychosis. Folia Psychiatr Neurol Jpn 27: 283-297, 1973

59. Neppe, VM: Carbamazepine in the Psychiatric patient. Lancet 2: 334, 1982

60. Neppe, VM: Carbamazepine as adjunctive treatment in nonepileptic chronic inpatients with EEG temporal lobe abnormalities. Clinical Psychiatry 44: 326-31, 1983

61. Dorn J: Possible synergestic action between carbamazepine and lithium carbonate in the treatment of a manic patient. Jefferson Journal of Psychiatry 2: 1983

62. Post, RM, Ballenger, JC, Uhde, TW, et al: Efficacy of carbamazepine in manic-depressive illness: Implications for underlying mechanisms. In Post RM, and Ballenger JC, Eds. Neurobiology of the Mood Disorders. Williams \& Wilkins, Baltimore. In press

63. Takezaki, H, and Hanaoka, M: The use of carbamazepine (Tegretol) in the control of manic-depressive psychosis and other manic, depressive states (in Japanese). SheishinIgaku 13: 173-183, 1971 
64. Hakola, H, and Laulumaa, V: Carbamazepine in treatment of violent schizophrenias. The Lancet, June 12, 1983

65. Forrest, D: Bipolar illness after right hemispherectomy. Arch Gen Psychiatry 39: 817-19, 1982

66. Stoudemire, A, Nelson, A, Houpt, J: Interictal schizophrenia-like psychoses in temporal lobe epilepsy. Psychosomatics 24: 331-339, 1983

67. Maffly, RH: Diabetes Insipidus. Disturbances in Body Fluid Osmolality. American Physiological Society, Bethesda, Md., 1977, pp 285-308

68. Wales, JK: Treatment of diabetes insipidus with carbamazepine. Lancet 2: 948-951, 1975

69. Brooks, SC, Lessin, BE: Treatment of resistant lithium induced nephrogenic diabetes insipidus and schzoaffective psychosis with carbamazepine. Am J Psych 140: 1077-1078, 1983

70. Post, RM, Pickar, D, et al: Effect of carbamazepine on CSF opioid activity: Relationship to antidepressant response. Psychiatry Research 5: 59-66, 1981 